Systemy Logistyczne Wojsk 53/2020

\title{
WAYS OF ENSURING MATHEMATICAL MODELLING OF PROCESSES IN THE \\ PREPARATION AND DECISION-MAKING IN THE COMBAT SERVICE \\ (LOGISTICS) SUPPORT SYSTEM OF TROOPS (FORCES)
}

\author{
Denys Valentynovych LISOVENKO \\ ORCID: 0000-0002-0006-8035 \\ Odessa Military Academy \\ Vitaliy DRUZHYNIN \\ ORCID: 0000-0001-8254-1836 \\ Odessa Military Academy
}

\begin{abstract}
The main management problems arising in the implementation of the preparation and decision-making processes in military systems have been considered; an approach to increase the efficiency and the validity of decisions, taking into account the most important factors and parameters of the real process, has been proposed.
\end{abstract}

Keywords: military system, factors and parameters of the real process, combat service (logistics) support system, mathematical modeling

\section{Introduction}

One of the main factors determining the success of combat actions in modern operations (combat actions) is the effective control of forces, weapons, and supplies. The integration of the logistics support system of the Armed Forces of Ukraine (AFU) with NATO standards and the reorganization requires officials of the combat service (logistics) control facilities of the Armed Forces of Ukraine not only to work faster when making appropriate decisions, but also to use modern software and mathematical models of real processes.

Scientific substantiation of the ways and means of improving the management quality of forces and weapons in military systems, as a rule, is based on the methods of quantitative assessments of the effective functioning of such systems.

Today, the question of the ability of command strength to quickly and reasonably make decisions on the effective combat use of troops and forces is becoming more and more relevant in military systems.

In order to assess the effectiveness of the functioning of the combat service (logistic) support system (CSSS) of troops (forces) in the Armed Forces of Ukraine and to find ways to create and to optimize this system, it is not enough to use indicators reflecting the general properties of such a system. There are a lot of such indicators.

Even with the availability of automation tools, the lack of modern software and mathematical models for calculating the corresponding indicators create difficulties in predicting the results of 
combat actions, preparing alternative solutions for the combat service (logistic) support of troops (forces), assessing them and choosing the best option.

\section{Functioning of the support system for the combat service in the operation}

A large number of factors and parameters of the real process of the combat service (logistic) support (in accordance with the purpose of the operation) significantly affect the efficiency of such a process. From the point of view of the main task that the combat service (logistic) support system of troops (forces) in operations (combat actions) solves, it is necessary to identify and to take into account a finite number of factors and parameters of the real process that characterize the main properties of the military system at the most important time (period) operations (combat operations).

It should be noted that the lack of adapted mathematical models for calculating the indicators of the combat service (logistic) support process in various control levels of the Armed Forces determine the feasibility of developing proposals to improve the work of the combat service (logistics) control facilities to assess the effectiveness and to choose a rational solution for organizing the combat service (logistics) support using the method of taxonomic analysis.

In terms of the main task that the combat service (logistics) support system of troops (forces) solves in operations (combat actions), it is necessary to identify and to take into account a finite number of factors and parameters of a real process that characterize the main properties of a military system. Such factors and parameters will be considered significant, and the completeness of their accounting can be determined as a function of their number and significance (Horodnov, Drobaha, Yermoshyn, Smirnov, Tkachenko, 2004). This fact identifies the need to select a set of factors and parameters that significantly affect the efficiency of the combat service (logistics) support system and which are necessary for a comparative assessment of alternative options for the decision taken.

In other words, in order to make it possible to predict the expected results of the operation of the combat service (logistics) support system in the process of command and control, it is necessary to develop an instrument for the practical solution of such a task.

In order to make it possible to predict the expected results of the operation of the combat service (logistics) support system in the process of command and control, it is necessary to develop a tool for the practical solution of such a task.

For the formalization and operational formulation of such a model, based on the study of the conditions for the preparation and conduct of modern operations, the experience of conducting Command Post Exercise, Research Command Post Exercise, and Command Field Exercise, as well as data that it is advisable to obtain by the method of expert assessments from representatives of the Command of Logistics, Rear, and Armaments Forces, officers of the Main Directorate of Operational 
Support of the Armed forces of Ukraine, and officers of the combat service (logistics) control facilities of various levels of command, significant factors and parameters of the real process, which significantly affect the functioning of the combat service (logistics) support system of troops (forces) of the Armed Forces of Ukraine (Table 1) and based on (Vlasova, 2002; Cherepanov, 1988) - their importance (significance) are determined.

At the same time, the very combat service (logistics) support system of troops (forces) does not inflict losses on the enemy and does not protect its troops from enemy attacks. But the result of combat actions of troops (forces) in an operation (combat actions) will depend on how effectively the combat service (logistics) support system will solve combat missions by making reasonable and rational decisions. It should also be noted that the result of the functioning of the combat service (logistics) support system of troops (forces), which can be determined at the decision-making stage, will largely affect the effectiveness of the performance of combat missions by forces and means of rear (logistics). In this regard, it becomes necessary to determine the influence of external and internal factors on the efficiency of the functioning of the combat service (logistics) support system of troops (forces).

The determination of the most significant factors and parameters of the real process, on which the quality of the performance of the main functions of such a system depends, is carried out in order to find the main indicators of the effectiveness of the functioning of the combat service (logistics) support of troops (forces).

Table 1. The list of significant factors and parameters affecting the functioning of combat service (logistics) support system in an operation (combat operations)

\begin{tabular}{|c|l|c|}
\hline Item & \multicolumn{1}{|c|}{ Name of factors and parameters } & $\begin{array}{c}\alpha_{i} \text { factor (parameter) } \\
\text { loading }\end{array}$ \\
\hline 1 & $\begin{array}{l}\text { The volume of cargoes delivered on time by type of property, directions, and stages of the } \\
\text { operation (combat operations) }\end{array}$ & 0.0619 \\
\hline 2 & $\begin{array}{l}\text { Load of supply directions at different periods and stages of an operation (combat } \\
\text { operations) }\end{array}$ & 0.0607 \\
\hline 3 & $\begin{array}{l}\text { The volume of timely delivered goods by type of property, taking into account the stability } \\
\text { of the combat service (logistics) support system }\end{array}$ & 0.0588 \\
\hline 4 & Permissible time of operation of the combat service command point (CP) in one place & 0.0570 \\
\hline 5 & Stability of functioning of the combat service (logistics) support system & 0.0533 \\
\hline 6 & Technical reliability of vehicles of the combat service (logistics) support units & 0.0502 \\
\hline 7 & Communication node survivability of the combat service command point (CP) & 0.0495 \\
\hline 8 & Available time resource for performing tasks for the combat service (logistics) support & 0.0409 \\
\hline 9 & Time required to complete tasks & 0.0384 \\
\hline 10 & $\begin{array}{l}\text { Availability of spare means/channels for transmission and reception of the necessary } \\
\text { information on the combat service (logistics) support }\end{array}$ & 0.0384 \\
\hline 11 & $\begin{array}{l}\text { Number of spare means/channels for transmission and reception of the necessary } \\
\text { information on the combat service (logistics) support }\end{array}$ & 0.0378 \\
\hline 12 & Availability of alternate routes for the delivery of supplies and recovery of casualties & 0.0272 \\
\hline 13 & The ability to use precision-guided weapon by the enemy & 0.0328 \\
\hline 14 & The ability to use local infrastructure to carry out logistics activities & 0.0297 \\
\hline
\end{tabular}




\begin{tabular}{|r|l|c|}
\hline 15 & $\begin{array}{l}\text { Possibilities of grouping enemy reconnaissance asset to expose of the combat service } \\
\text { (logistics) support system elements }\end{array}$ & 0.0291 \\
\hline 16 & $\begin{array}{l}\text { Stability of the combat service (logistics) support system to the effects of enemy EW } \\
\text { means }\end{array}$ & 0.0285 \\
\hline 17 & Possibilities of EW grouping of their troops & 0.0279 \\
\hline 18 & Types and number of logistics support being repaired & 0.0180 \\
\hline 19 & The existing shortage of logistics support and stocks of supplies & 0.0173 \\
\hline 20 & The ability to use camouflage and protection due to terrain properties & 0.0149 \\
\hline 21 & The attitude of the local population to the military unit of the Armed Forces of Ukraine & 0.0149 \\
\hline 22 & The ability to use local infrastructure to carry out logistics activities & 0.0142 \\
\hline 23 & Preparedness of combat service (logistics) control facilities & 0.0136 \\
\hline 24 & Status and training of administrative units & 0.0136 \\
\hline$\ldots$ & & \\
\hline 27 & Other factors & 0.0040 \\
\hline
\end{tabular}

Source: Own elaboration

It is customary to consider factors and parameters that significantly affect the result of the functioning of the combat service (logistics) support system of troops (forces) as significant factors and parameters of the real process.

In order to ensure further correct roughening of the developed models, the set of factors and parameters of the simulated processes should be presented in the form of a scale of significant factors and parameters. Significant factors and parameters are provided in decreasing order of their relative weight (Table 1), which characterizes the significance of each factor to achieve the goal of modeling (Gorodnov, 1987).

The use of a scale of significant factors and parameters as the basis for improving the model for evaluating the effectiveness and choosing the optimal version of the logistics support system cannot guarantee coverage of all the features of the simulated processes.

\section{Conclusion}

At the same time, taking into account the factors and parameters presented makes it possible to avoid major strategic mistakes, since in the future, it makes it possible to visually perform a comparative assessment of the composition of existing and developed performance indicators and parameters while assessing the degree of their influence on the outcome of the functioning of the combat service (logistics) support system of troops (forces).

The presented proposals can be implemented both at the current stage of the development of the combat service (logistics) control facilities of the headquarters of various command levels and in the perspective of their development and the transition of the combat service (logistics) support system to NATO standards. 


\section{BIBLIOGRAPHY}

[1] Smolych, P. I., Yakovenko, A. S., Babaryha, A. S. (2017). A Common Logistics Approach for Military Commitment Involved in International UN Peace and Security Operations: Study Aid. - K.: NDUU named after Ivan Cherniakhovskyi, 68.

[2] Horodnov, V. P., Drobaha, H. A., Yermoshyn, M. O., Smirnov, Ye. B., TKaChenKo, V. I. (2004). Modeling of Combat Actions of Air Defense Troops (Forces) and Information Support of Their Control Processes (Theory, Practice, History of Development). Monograph. - Kharkiv: KhMU, 409.

[3] Vlasova, K. P. (Ed.) (2002). Research Methods and Organization of Experiments. Kharkiv: Publishing House of the Humanitarian Center, 255.

[4] Cherepanov, V. S. (1988). Expert Assessments in Educational Research. Pedagogika, 152.

[5] Gorodnov, V. P. (1987). Modeling of Combat Actions of Units, Forces, and Formations of Air Defense Troops. VIRTA PVO, 380. 